\title{
Similarities between a manuscript in Clin Oral Invest (published online 21 July 2015; DOI 10.1007/s00784-015-1530-4) and a former publication (J Investig Clin Dent 2010;1(2):126-32. doi: 10.1111/j.2041-1626.2010.00026.x.)
}

\author{
Gottfried Schmalz ${ }^{1}$
}

Received: 20 October 2015 / Accepted: 23 October 2015 /Published online: 16 November 2015

(C) Springer-Verlag Berlin Heidelberg 2015

It has been recently brought to the editor-in-chief's attention that the following article:

Nickles K, Scharf S, Röllke L et al. (2015). Detection of subgingival periodontal pathogens-comparison of two sampling strategies. Clin Oral Invest, published online 21 July 2015; DOI 10.1007/s00784-015-1530-4

has significant similarities in the text with the article:

Wohlfeil M, Tabakci O, Arndt R, Eickholz P, Nickles K (2010) Detection rates of presumptive periodontal pathogens in subgingival plaque samples of untreated periodontitis using either four or six pooled samples. J Invest Clin Dent 1: 126-132

This has been scrutinized by the editor-in-chief of this journal. An iThenticate analysis performed by the publisher showed a $28 \%$ similarity of the 2015 publication with the above-mentioned article in the J Invest Clin Dent 2010.

After a more detailed analysis of the similarities, it was found that they are located for parts of sentences in the Abstract and for some sentences/part of sentences in the Introduction part of the two publications. A number of similarities were found in the Material and Methods part, few in the Results part and again a number of similarities concerning parts or whole sentences in the Discussion part between the two publications.

The general topic of the two publications is quite similar. However, the data presented in the publication in Clinical Oral Investigations 2015 are substantially different from the data set in the J Invest Clin Dent 2010. Both studies were performed on different patient collectives. The number of cases

Gottfried Schmalz

gottfried.schmalz@klinik.uni-regensburg.de

1 University of Regensburg, Regensburg, Germany is different and different test systems have been used: IAI Pado in the 2010 publication and microIDent in the 2015 publication. Furthermore, the publication from 2010 is cited in the reference list of the publication from 2015.

According to the COPE guidelines ("How to deal with text recycling"), "some degree of text recycling in the background/ introduction section of an article may be unavoidable, particularly, if an article is one of several on a related topic" [1]. For the part Material and Methods, it is stated that the "use of similar or identical phrases in methods sections where there are limited ways to describe a method is not unusual." For the Discussion part, it says in the COPE guidelines, "some degree of text recycling may be acceptable in the discussion; however, as the majority of the discussion should focus on putting the results of the current study in context, large amounts of text recycling is unlikely to be acceptable, especially if previously published ideas are presented as new."

According to our assessment, concerns are indeed substantiated related to text similarities in the Discussion part of the two publications. However, as complete different data sets have been reported in the two publications and the 2010 publication was cited in the reference list of the 2015 publication, a retraction is not in line with the COPE guidelines [1]. There it says that a correction is adequate, if despite text similarities, "there is still sufficient new material in the article to justify its publication." This has been checked by the responsible Associate Editor and agreed upon. Since the beginning of 2015, all manuscripts submitted to Clinical Oral Investigations are checked by iThenticate

\section{Reference}

1. How to deal with text recycling. http://publicationethics.org/files/ BioMed\%20Central_text_recycling_editorial_guidelines.pdf 